\title{
DELIBERATIVE DEMOCRACY AND PUBLIC REASON
}

Kenneth Baynes*

\begin{abstract}
The article reexamines Habermas's conceptions of deliberative politics and procedural democracy in light of other deliberative theories, so as to explore their similarities and differences and to investigate their indebtedness to the idea of public reason and the practical implications of that idea.

KEYWORDS - Deliberative democracy. Liberalism. Proceduralism. Public reason.
\end{abstract}

RESUMO - O artigo reexamina as concepções habermasianas de política deliberativa e democracia procedimental à luz de outras teorias deliberativas, de forma a explorar as suas semelhanças e diferenças e investigar o quanto devem à ideia de razão pública e as implicações práticas daquela ideia.

PALAVRAS-CHAVE - Democracia deliberativa. Liberalismo. Procedimentalismo. Razão pública.

Among normative theories of democracy, the idea of a deliberative democracy is a relatively new kid on the block - though one that has already received a fair amount of attention. ${ }^{1}$ Those who claim the label, however, reflect a variety of different political persuasions, and deliberative theorists have had a difficult time identifying what makes

* Professor, Dept. of Philosophy and Political Science, Syracuse University.

1 See, in the rapidly expanding literature, Joshua Cohen, "Deliberation and Democratic Legitimacy". In: The Good Polity, ed. by Alan Hamlin and Philip Pettit (Blackwell, 1989), p. 17-34; James Fishkin, Democracy and Deliberation (New Haven: Yale, 1991); Joseph Bessette, The Mild Voice of Reason: Deliberative Democracy and American National Government (Chicago: University of Chicago Press, 1994), Amy Gutmann and Dennis Thompson, Democracy and Disagreement (Cambridge: Harvard University Press, 1996); John Dryzek, Deliberative Democracy and Beyond (New York: Oxford University Press, 2000); and the two collections, Deliberative Democracy, ed. by James Bohman and William Rehg (Cambridge: MIT Press, 1997) and Deliberative Democracy, ed. by Jon Elster (New York: Cambridge University Press, 1998). See also the review essay by Samuel Freeman, "Deliberative Democracy: A Sympathetic Comment", Philosophy and Public Affairs, 29 (2000), 371-418.

\begin{tabular}{|l|l|l|l|l|l|}
\hline Veritas & Porto Alegre & v. 55 & n. 1 & jan./abr. 2010 & p. 135-163 \\
\hline
\end{tabular}


this conception distinct from its various competitors. ${ }^{2}$ It is also an idea that has recently been the focus of important criticisms, even by those generally supportive of its aims. ${ }^{3}$ In Between Facts and Norms Habermas introduces his own conception of a "deliberative politics" and "procedural democracy" that has much in common with other deliberative theorists. In the following I wish to explore this conception, noting some of its similarities and differences from other conceptions. I will then consider how it fares against some objections and reservations that have been made against deliberative conceptions generally. In the final sections, I take up the idea of public reason with which the idea of deliberative democracy is closely associated and consider briefly some of the more practical implications of that idea.

\section{The idea of a deliberative democracy}

The aim of a conception of deliberative democracy is to specify a broad set of procedures and conditions for reaching collectively binding decisions that are both legitimate and presumptively correct (or rationally acceptable). In general, deliberative theorists focus on the (formal and informal) processes that precede the final act of decision-making, rather than concentrating on a more narrowly conceived process of aggregating voter preferences. Legitimacy, for them, derives not simply from the act of voting, but from broader processes that lead up to the act of voting as well. ${ }^{4}$ As with other normative conceptions, it is primarily conceived as a set of ideal procedures in light of which existing institutions and practices could be criticized and assessed.

Joshua Cohen has offered one concise formulation of such an "ideal deliberative procedure" that lies at the core of his conception of deliberative democracy. "A democratic conception can be represented in terms of the requirements that it sets on such [an ideal] procedure. In particular, outcomes are democratically legitimate if and only if they could be the object of a free and reasoned agreement among equals. The ideal deliberative procedure is a procedure that captures this principle" (22). Johnson and Knight have offered a comparable ideal: "We view deliberation as an idealized process consisting of fair procedure within which political

2 See David Estlund, "Who's Afraid of Deliberative Democracy?", Texas Law Review, 71 (1993), p. 1437-477.

3 Jack Knight and James Johnson, "Aggregation and Deliberation: On the Possibility of Democratic Legitimacy", Political Theory, 22 (1994), p. 277-296.

4 Manin, "On Legitimacy and Political Deliberation," Political Theory 15 (1987); for a more recent sketch, which distinguishes sharply between the role of deliberation and the act of voting, see Richard Vernon, Political Morality (New York: Cambridge Univerisity Press, 2001). 
actors engage in reasoned argument for the purpose of resolving political conflict". ${ }^{5}$ Among the "fair procedures" Johnson and Knight include the requirement of "manifestly free and equal access to relevant deliberative arenas for purposes of establishing procedures, setting the agenda, and making final decisions" (285). Their conception differs from Cohen's primarily in its departure from a notion of consensus or agreement as a regulative aim of deliberation. (A point to which I will return below.) Finally, Samuel Freeman defines a deliberative democracy as "one in which political agents or their representatives (a) aim to collectively deliberative and vote (b) their sincere and informed judgments regarding (c) measures conducive to the common good of citizens". ${ }^{6}$ Central to all these views is the idea of "a process of public reasoning about the common good" (336) and it is this feature that most distinguishes it from the liberal-pluralist or "aggregative" alternative.

The conception of a deliberative democracy can also be supported by somewhat differing considerations. For Cohen, "the notion of a deliberative democracy is rooted in the intuitive ideal of a democratic association in which the justification of the terms and conditions of association proceeds through public argument and reasoning among equal citizens". The motivation behind this conception, then, is predominantly a notion of public justification among free and equal citizens. Others, such as David Estlund, have argued that the "key" to the conception of a deliberative democracy is "the idea of true or false judgments about political justice". ${ }^{7}$ Deliberation involves a "pooling of judgments" (Michelman) not a mere aggregation of interests. It is thus this cognitive or epistemic feature that is central to the conception. Still other deliberative theorists stress the unique conception of citizenship and particular virtues or qualities of citizenship as a distinguishing feature in a deliberative conception. ${ }^{8}$ Although each of these considerations points to important aspects of a deliberative conception, in the following I shall argue that what is most distinctive about a deliberative conception is the way in which it seeks to capture (in a set of ideal procedures) an abstract conception of the freedom and equality of citizens. Its primary difference, then, from both liberal-pluralist and "radical" (or participatory) alternatives is the

5 "Aggregation and Deliberation," p. 285.

6 Freeman, p. 382.

7 Estlund,"Who's Afraid of Deliberative Democracy", p. 1476; see also Estlund, "Beyond Fairness and Deliberation: The Epistemic Dimension of Democratic Authority" in Deliberative Democracy, ed. by Bohman and Rehg, and Estlund, "Political Quality" in Democracy, ed. by Ellen Frankel Paul, et al. (New York: Cambridge University Press, 2000), p. 127-160.

8 See, for example, Bissette, The Mild Voice of Reason, or Gutmann and Thompson's emphasis on the civic virtue of reciprocity, Democracy and Disagreement, p. 359. 
way in which this (more) abstract conception is used to shape the ideal procedures.

If we begin with what Johnson and Knight call the "standard case" for deliberative democracy, several features can be noted. (1) A deliberative conception views the democratic process as one that is concerned with the common good, where this is not identified exclusively with a notion of aggregate interests or collective goods. ${ }^{9}$ Although politics is not solely oriented to it, the idea of the common good is given a more prominent normative role than it is within liberal conceptions. (2) In response to the longstanding question of whether law is best conceived as voluntas or ratio, deliberative conceptions come down on the side of ratio. A central means by which the common good is discerned and/or "fashioned" (Johnson and Knight) is a deliberative process that places a high premium on reason and argumentation. Further, the relevant notion of reason is not simply instrumental (or Humean) in character, but includes as well the idea that its exercise is "truth-tracking" or at least "reasonable" in a more substantive sense. (3) A central assumption of a deliberative conception is that the deliberations that take the common good as their focus do not simply treat individual preferences as exogenous elements of the political system. Rather, it assumes that in the process of reasonable deliberation, the search for a common good will often result in the transformation and/ or "laundering" of merely private preferences. "Preferences do not exist independently of the institutions through which they are expressed; their formation is at least partially endogenous to the process of agenda formation, which must, therefore, be seen as a deliberative rather than as a purely aggregative mechanism". ${ }^{10}$ (4) Finally, deliberative democracy invokes a different conception of citizen motivation than that found in the liberal-pluralist model. What motivates citizens is not simply self-interest constrained by the recognition of some principles for mutual advantage, but an interest in finding the common good and a "higher-order" desire to justify claims to others who share such an interest.

Not surprisingly, each of these elements has been challenged either by recalling earlier criticisms of the "classical conception of democracy" or by indicating new difficulties that are uncovered with the aid of theories of collective or social choice. (1) At least since Schumpeter, the notion of a unique and determinate common good as the object and expression of the will of the people has been frequently criticized. "There is no such thing as a uniquely determined common good that all people could agree on or be

9 "Aggregation", p. 281; see also Cohen, p. 24-25.

10 Beitz, Political Equality (Princeton: Princeton University Press, 1989), p. 12-13; see also Cass Sunstein, "Preferences and Politics" , Philosophy and Public Affairs, 20 (1991). 
made to agree on by the force of rational argument". ${ }^{11}$ Such a conception is in conflict with what Schumpeter calls the "irreducible differences of ultimate values which compromise could only maim and degrade" (155). Moreover, theorists of collective choice have repeatedly demonstrated that even if there were a sufficiently determinate conception of the common good (or "general will") it cannot be construed as the outcome of any minimally defined set of democratic procedures. ${ }^{12}$ Deliberativists respond that neither a recognition of the "fact of pluralism" (if this is not itself already taken to imply value skepticism) nor the theorems of social choice theory require rejecting a notion of the common good. While the common good may not be a unique and determinate ideal that can be specified independently of any (ideal) procedures, deliberativists would also reject defining the common good in exclusively proceduralist terms (as the social choice theorist's objection assumes). ${ }^{13}$ The more plausible interpretation is that the common good (or general will) describes a general scheme or framework that provides both a focus for deliberation and includes at least those (not exclusively procedural) rights and values that are conditions for deliberation itself. ${ }^{14}$ (2) The characterization of deliberative democracy as "cognitive" or "epistemic" has also been the focus of criticism. The idea that deliberation is concerned with a "pooling of judgments" and that one can talk about the truth (or at least the reasonableness) of political outcomes in more than an instrumentalist fashion strikes many as, at best, misguided and, at worst, pernicious. It encourages the view that democracy as a procedure might then be replaced by political elites who are better able to discern the correct (true) outcomes of democratic deliberation. ${ }^{15}$ Others (such as Jon Elster) object that there may be reason to doubt that more reasoning and deliberation will necessarily yield better political outcomes. ${ }^{16}$ In response to these and other objections, deliberativists divide: Some (Estlund) think that commitment to a procedurally-independent notion of political truth is sine qua non of deliberative politics, but that this commitment can be fit

11 “Two Concepts of Democracy". In: Political Philosophy, ed. by A. Quinton (New York: Oxford University Press, 1967), p. 154.

12 See William Riker, Liberalism against Populism (San Francisco: W. H. Freeman, 1982), and the discussion in Jules Coleman and John Ferejohn, "Democracy and Social Choice", Ethics, 97 (1986), p. 6-25 and David Miller, "Deliberative Democracy and Social Choice", Political Studies, 40 (1992), p. 54-67.

13 See especially Joshua Cohen, "An Epistemic Conception of Democracy," Ethics, 97 (1986), p. 26-38.

14 Ibid. and Samuel Freeman, "Deliberative Democracy", p. 376.

15 See Estlund, "Who's Afraid of Deliberative Democracy", p. 1452.

16 "The Market and the Forum: Three Varieties of Political Theory". In: Deliberative Democracy, Bohman and Rehg, p. 14. 
within a democratic process given that it is not the only relevant political value. ${ }^{17}$ Others, by contrast, are more sanguine about the epistemic benefits of democracy itself, even if actual democratic procedures are at best imperfect procedures (Cohen and Habermas). What nonetheless unites these recent conceptions of deliberative democracy is the idea that deliberation, as process of reasoning and argumentation, involves an exchange of reasons that cannot in the end be reduced to the expression of individual preference. (3) and (4): Finally, others have been critical of the strong assumptions concerning the transformation of individual preferences and/or the civic virtues presupposed in at least some deliberative conceptions, suggesting that they are either extremely utopian or that they assume too high a degree of homogeneity, or both. Deliberativists, in turn, have responded that it is rather the potential for preference transformation that is important and that, in many cases, the earlier republican or civic humanist stress on virtue can be replaced or at least mitigated by more explicit attention to institutional design.

\subsection{Habermas's "procedural democracy"}

The conception of a "procedural democracy" and "deliberative politics" introduced by Habermas in Between Facts and Norms shares, in some form, all these features of a deliberative democracy. Politics is concerned, at least in part, with the common good and processes of deliberation have as their primary focus, at least some of the time, the common good or "generalizable interests". This conception of democracy is also "cognitive" in that it is concerned with specifying procedures for collective decision-making that have a presumption of rational outcomes (BFN, 285). Habermas also argues that democratic procedures should specify not simply a means for aggregating pre-political preferences but the conditions of deliberation in which agreement about "generalizable interests" can be pursued, at least in part through the transformation of preferences. Finally, though Habermas puts less emphasis on this feature, the realization of a deliberative politics assumes that individuals have motivations other than those of self-interest. Democratic procedure requires a "rationalized lifeworld" including a liberal political culture and corresponding civic virtues that, as he puts it, "meets it halfway". In fact, with respect to each of these features of a deliberative democracy, Habermas is inclined to give them a more procedural interptretation. This is particularly evident in his attempt to distinguish his position from both the liberal and republican alternatives. It will thus be helpful to consider

17 Estlund, "Beyond Fairness and Deliberation" and Estlund, "Political Quality". 
first the sense in which Habermas's conception of democracy is - and is not - procedural.

"Procedural" and "proceduralist" are among the most commonly used adjectives in Habermas's Between Facts and Norms. He broadly contrasts his preferred "proceduralist legal paradigm" to the liberal and welfarist paradigms (BFN, 409). He speaks of a "procedural understanding of the constitution" (BFN, 246), a "proceduralist" view of constitutional adjudication, a proceduralist understanding of law (BFN, 409), a proceduralist theory of politics (BFN, 273), and a procedural interpretation of popular sovereignty (BFN, Appendix I). He also describes his own conception of democracy as "proceduralist". Within the context of German discussions, it is clear that Habermas's primary concern is to distance himself from a material value-ethics interpretations of the law and political process, interpretations inspired by the work of Max Scheler and Nicolai Hartman (BFN, 254). Habermas also uses the term "procedural" to distinguish his own conception of the democratic process from liberal and republican alternatives. This is partly to distinguish his position from one that takes as fixed and given a "pre-political" set of (natural) rights and from one that has the democratic process derive its legitimacy "from the prior agreement of a presupposed substantial-ethical community" - that is, from a prior agreement on a conception of the good. Thus, Habermas writes, "a consistent proceduralist understanding of the constitution bets on the intrinsically rational character of the procedural conditions grounding the supposition that the democratic process as a whole facilitates rational outcomes. In that case reason is embodied solely in the formal-pragmatic facilitating conditions for deliberative politics" (BFN, 285).

However, within the wider context of legal and democratic theory, the term 'procedural' is ambiguous and there are many different conceptions that have been described as proceduralist that differ importantly from Habermas's own. For example, in his influential essay, "Is Democracy Special?", Brian Barry describes his own conception as proceduralist which he understands to mean a rejection of "... the notion that one should build into 'democracy' any constraints on the content of the outcomes produced, such as substantive equality, respect for human rights, concern for the general welfare, personal liberty, or the rule of law. The only exception (and these are significant) are those required by democracy itself as a procedure". ${ }^{18}$ While the question of what is "required by democracy itself as a procedure" is itself a matter of much debate, Habermas's conception of democracy is not procedural in this

18 In Philosophy, Politics, and Society, ed. by P. Laslett (Oxford: Blackwell, 1979), p. 155-156. 
sense. It clearly entails more substantive normative content than Barry would want.

Further, even normatively richer procedural conceptions, such as Peter Singer's conception of democracy based on a notion of "fairness as compromise" or John Ely's "process-oriented approach" to the constitution and constitutional review, fall short of Habermas's conception. ${ }^{19}$ For these conceptions, the democratic process consists in a set of rules and procedures that are supposed to weigh equally preferences whose formation is largely exogenous to the democratic process itself. Each person should be granted the opportunity to register her preference and no person's preference should count for more than another person's. The conceptions thus operate with an ideal of political equality understood in terms of the equal opportunity to influence political outcomes. A procedure is "fair" if it captures this notion of equal power. The difficulty with such conceptions, however, is that they remain relatively indifferent to the initial preferences that enter into the procedure. ${ }^{20} \mathrm{~A}$ fuller and thus more adequate account would consider the formation and quality of preferences as well. To do this, the ideal of political equality must initially be conceived at a more abstract level and cannot be identified directly with the (procedural notion of the) equal opportunity to influence outcomes. ${ }^{21}$

Habermas's conception of democracy thus assumes a more abstract ideal of political equality and the aim is then to capture this more abstract ideal in a set of ideal procedures thereby considered "fair". The ideal of political equality is, however, not equated with a set of procedures that secures an equal opportunity (for any given preference) to influence outcome. "Rather, the claim that a norm lies equally in the interest of everyone has the sense of rational acceptability: all those possible affected should be able to accept the norm on the basis of good reasons" (BFN, 103). In this sense, Habermas's procedural conception is perhaps closest to what Charles Beitz has called "complex proceduralism":

Like other forms of proceduralism, [complex proceduralism] holds that democratic procedures should treat persons as equals; but it will not follow that the appropriate criterion for assessing procedures is the simple principle of equal power over outcomes. Instead, complex proceduralism holds that the terms of democratic participation are fair when they are reasonably acceptable from each citizen's point of view, or more precisely, when no citizen has good reason to refuse to accept them. ${ }^{22}$

19 See Peter Singer, Democracy and Disobedience (NY: Oxford University Press, 1974) and John Hart Ely, Democracy and Distrust (Cambridge: Harvard University Press, 1980).

20 See Charles Beitz, Political Equality (NJ: Princeton University Press, 1989), p. 82.

21 See, for example, Habermas's remark linking the notion of equal respect with the idea of reasons acceptable to all (BFN, 103).

22 Beitz, p. 23. 
In Habermas's conception, analogously, there are certain abstract ideals - in the last analysis an ideal of (public and private) autonomy or communicative freedom - that are identified prior to (and thus independently of) any proposed set of (ideal) procedures. Habermas nonetheless describes his conception as procedural for two reasons: First, in contrast to a material value-ethics, Habermas claims that the fundamental ideal that forms the "dogmatic core" of his theory - the idea of communicative freedom or autonomy - is not itself simply one value among others, but reflects a basic norm implicit in the very idea of communicative action (BFN, 445-446). Second, he claims that this ideal - developed in Between Facts and Norms in connection with the co-equal and mutually interdependent ideas of public and private autonomy - can in turn be expressed in a set of (ideal) democratic procedures. It is because the procedures adequately mirror this basic ideal, however, that we are entitled to confer a presumption of reasonableness or fairness upon them. ${ }^{23}$ In sum, then, for Habermas, ideal procedures attempt to capture or express an ideal or model-conception of the citizen as free and equal or, what amounts to the same thing, an ideal of practical reason.

\subsection{The "co-originality thesis": Democracy and liberal values}

Habermas's procedural or 'discourse' conception of democracy, as outlined in chapter four, provides a basis for reconsidering the longstanding dispute concerning the relation between democracy and other liberal values or, in Benjamin Constant's phrase, the liberty of the ancients and the liberty of the moderns. In Between Facts and Norms Habermas argues that neither the "principle of democracy" nor the basic scheme of (liberal) rights should be seen as primary. Rather, as he puts it, the principle of democracy and the basic scheme of rights are "co-original" (or "equiprimordal") and emerge together via the "interpenetration of the discourse principle and the legal form" (BFN, 121). As Habermas sees it, this enables his conception to avoid the two extremes of a legal positivism that leaves basic rights up to the political sovereign, on the one hand, and a subordination of popular sovereignty to a prior moral principle as in, for example, Kant and the natural law tradition, on the other. "The universal right to equal liberties may neither be imposed as a moral right that merely sets an external constraint on the sovereign legislator, nor be instrumentalized as a functional prerequisite for the legislator's aims" (BFN, 104). Thus, the "co-originality thesis" regards public autonomy (roughly, the idea that citizens can be bound only by

${ }^{23}$ See BFN, p. 295 and Habermas, "Three Models of Democracy", Constellations, 1 (1994), p. 6. 
laws that they give to themselves) and private autonomy (roughly, civil and political rights) as reciprocally dependent on each other such that neither can claim a prior or independent status.

In an extended comparison between Habermas's views and his own, Joshua Cohen endorses (as also, incidentally, does Rawls) this idea of the 'co-originality' or 'equiprimordiality' of public and private autonomy. ${ }^{24}$ However, he is less convinced by the specific arguments in support of it. In particular, he suggests, first, that Habermas's account appeals to a "comprehensive doctrine" or philosophy of life that is inappropriate given the "fact of reasonable pluralism" and, second, that it is deficient in its support for an equal right to liberty. Cohen's alternative account of the relation between basic liberties and democracy is highly instructive and strengthens the co-originality thesis. However, given that Habermas has elsewhere acknowledged that there is a substantive "dogmatic core" to his theory - the idea of communicative freedom or autonomy - I do not think it necessary to read him in the more procedurally minimalist manner that Cohen proposes. In fact, my account of Habermas's distinctive use of the term 'procedural' above is intended to resist such an interpretation.

Cohen's first reservation is plausible in that Habermas's account of political legitimacy is presented within the wider framework of his theory of communicative action. It would thus seem to be a "comprehensive" rather than "political" account that appeals to considerations that not all politically reasonable citizens would acknowledge. ${ }^{25}$ However, an alternative reading is possible: The "interpenetration of the discourse principle and the legal form" can itself be seen as a restriction of the more abstract conception of autonomy to the political-legal context and thus as first introducing the idea of "legal consociates". ${ }^{26}$ In Habermas's own variation on the social-contract tradition, the guiding question then becomes, "What basic rights must free and equal citizens mutually accord one another if they want to regulate their common life legitimately by means of positive law?". ${ }^{27}$ Further, this question must be addressed, so to speak, from within - that is, without appeal to substantive philosophies of

24 "Reflections on Habermas on Democracy", Ratio Juris, 12 (1999), p. 385-416; for Rawls's views on the "co-originality" thesis, see "Reply to Habermas" in Political Liberalism, p. 412.

25 Rawls also objects that Habermas's theory is 'comprehensive' and not 'political', in "Reply to Habermas".

26 This interpretation is further supported by the fact that, in BFN, Habermas specifically introduces the discourse principle at a quite abstract level, prior to its formulation as a moral principle (Principle $U$ ) or in connection with the question of political legitimacy (BFN, 107-108).

27 BFN, 82; "Remarks on Legitimation through Human Rights", Philosophy and Social Criticism, 24 (1998), p. 160. 
life (or comprehensive doctrines) that other citizens cannot reasonably be expected to endorse. Thus, unlike earlier contract theorists (including at least some readings of Rawls), this question cannot be settled by appeal to particular interests of the parties nor by appeal to a set of "natural" (pre-political) rights, but, in the first instance, to considerations about what citizens would consent to in view of their status as free and equal persons:

Under conditions of postmetaphysical thinking, we cannot expect a furtherreaching consensus that would include substantive issues. This restriction to presuppositions that are formal in this sense is tailored for the specifically modern pluralism of worldviews, cultural forms of life, interest positions, and so forth. Naturally, this does not mean that a constitution-making practice of this kind would be free of all normative content. On the contrary, the performative meaning of this practice, which is merely set forth and explicated in constitutional principles and the system of rights, already contains as a doctrinal core the (Rousseausian-Kantian) idea of the selflegislation of voluntarily associated citizens who are both free and equal. ${ }^{28}$

As I will argue below in connection with the idea of public reason, this interpretation more or less parallels Rawls's idea that a "political conception" must not be "political in the wrong way". According to Cohen's second reservation, Habermas's commitment to equal liberties is insufficient since it too rests on his claim that the system of rights can be derived exclusively from "the interpenetration of the discourse principle and the legal form". Given that Cohen views the discourse principle as imposing a fairly general requirement of impartiality he is doubtful that its conjunction with the idea of the "rule of law" (or "legal form") will yield a sufficiently broad set of liberal rights (including, rights to conscience, bodily integrity, privacy, property, etc.) (390). Although it must be admitted that Habermas's argument here is less than clear, I believe that Cohen is reading Habermas's account in an excessively minimalist or proceduralist manner. If, as I have argued, the discourse principle itself reflects an (abstract) ideal of persons as free and equal, then it may impose more constraints than Cohen assumes. Further, the notion of the "legal form" that Habermas invokes, derived from legal debates in $20^{\text {th }}$ century German law, is also more substantive in character than the idea of the 'rule of law' more narrowly conceived and already includes something like the idea of equal subjective liberties. ${ }^{29}$ Thus, the

28 "Reply", in Habermas on Law and Democracy, ed. by M. Rosenfeld and A. Arato (Berkeley: University of California Press, 1998), p. 406.

29 See BFN, p. 84-89 and, more generally on this topic, William Scheuerman, Between the Norm and the Exception: The Frankfurt School and the Rule of Law (Cambridge: MIT Press, 1994). 
"interpenetration" strategy could arguably generate something like the liberties specified, for example, in Rawls's Principle of Equal Liberty. On the other hand, however, Cohen is correct to note that, on Habermas's account, the "interpenetration of the discourse principle and legal form" yields only a general scheme of basic rights and not a concrete set of liberties (393). Although this scheme is more detailed than Cohen assumes, it does not by itself provide the means for assigning specific weight to the reasons that citizens must consider when determining the more specific scope of the basic liberties. On Habermas's account, these are questions that citizens within a given polity must determine for themselves within the framework of a deliberative politics. Of course, citizens would have to give consideration to precisely the kinds of reasons - and the appropriate weighting among them - that Cohen raises in his own reflections on the relation between democracy and rights to religious, expressive, and moral liberty. ${ }^{30}$

\subsection{The role of consensus}

The idea of consensus plays an important role in Habermas's conception of a deliberative democracy as it does in other deliberative conceptions. As Cohen has expressed it, "Ideal deliberation aims to arrive at a rationally motivated consensus - to find reasons that are persuasive to all who are committed to acting on the results of a free and reasoned assessment of alternatives by equals". ${ }^{31}$ The aim of reaching agreement on the basic principles and terms of social cooperation reflects the conviction that the democratic process should not simply provide a mechanism for aggregating personal or pre-political preferences, but should provide a context for reasoned debate and discussion about the merits of policies and proposals in a way that recognizes the freedom and equality of each citizen. It is also claimed that a search for consensus is one way in which what Madison called the "mild voice of reason" can find expression within the political process. The idea of consensus, then, follows from a commitment to the freedom and equality of citizens and from a desire to improve the "reasonable quality" (BFN, 304) of democratic outcomes.

Nevertheless, the value placed on a search for agreement or consensus has not gone unchallenged by other democratic theorists. Some claim

30 See Cohen, "Democracy and Liberty" (in Elster, Deliberative Democracy) and, with respect to debates about pornography, "Freedom, Equality and Pornography," in Justice and Injustice in Law and Legal Theory, ed. by A. Sarat and T. Kearns (Ann Arbor: University of Michigan, 1996).

31 Cohen, "Deliberation and Democratic Legitimacy", p. 23. 
that, in a society characterized by the "fact of pluralism", it is both impractical and unreasonable as a goal, while others have pointed to the pernicious effects that could follow from an insistence on consensus. For example, Donald Moon, who describes his own version of "political liberalism" as "a variant of traditional consensus theories of legitimation, but one that does not share their faith in supposing that nonconsensuality can be overcome" (211), notes the risk in consent theory of "excluding certain voices, and so generating a false consensus". Similarly, in a critique of deliberative theories, Iris Young has also argued that the demand for consensus can exclude the viewpoints of others and promote cultural bias. ${ }^{32}$ Finally, James Bohman and William Rehg have criticized the prominent role given to the search for consensus in Habermas's theory, arguing that a "weaker interpretation of epistemic deliberation" is required for a multicultural society. ${ }^{33}$

Although these criticisms may apply to some models of deliberative democracy, in general I think they rest on a misunderstanding of the role of consensus. Neither Habermas nor Cohen, for example, claim that all social conflict or disagreement can be resolved in a consensus--not even, as Johnson and Knight suggest, "in the ideal case at least" (282). Cohen, for example, is quite explicit that, "even under ideal conditions there is no promise that consensual reason will be forthcoming" (23). ${ }^{34}$ The bulk of the political process, Habermas acknowledges, depends on compromise and on the outcome of fair procedures, including, as prominent among these, majority rule (BFN, 282). It is thus necessary to be more specific about the role (and motivation) of consensus as an aim of deliberation in this conception of democracy. Several brief observations are in order.

First, none of the theorists we have been considering suggest that political legitimacy requires or rests on a de facto consensus or agreement. For just the reasons Moon notes, such a consensus may be "false". Deliberative theorists, by contrast, speak of an ideal consensus that can be reached only if certain demanding conditions have been met. In this sense, the search for consensus functions primarily as a regulative idea that can only be approximately realized in practice. However, once the role of consensus is formulated in this way, it suggests that the real normative work is not being done by the idea of consensus but by other

32 "Communication and the Other: Beyond Deliberative Democracy", in Intersecting Voices (Princeton: Princeton University Press, 1997).

33 "Discourse and Democracy," in Discourse and Democracy, ed. by R. von Schomberg and K. Baynes (Albany: SUNY Press, 2002), p. 46.

34 For similar remarks, see also Cass Sunstein, "Beyond the Republican Revival," Yale Law Review, 97 (1988), p. 1555 and Frank Michelman,"Law's Republic," Yale Law Review, 97 (1988), p. 1527. 
ideals lying behind it. As I have suggested, the search for consensus reflects a commitment to the view that "the principles of political association should be justifiable to all whom they bind" (Larmore). It thus rests upon a deeper commitment to the freedom and equality of citizens and is not itself an independent goal or value.

Second, recognition of the (derivative) value of consensus as a regulative idea does not mean that agreement, even after extended deliberation, is to be reasonably expected on a wide-range of preferences or policies. There can be, however, no pre-set answer to the question of the scope or range of agreement since the search for consensus itself may lead to new insight and the discovery (or creation) of new bases for agreement. This, at least, is the hope that deliberativists hold out: Unlike the liberal-pluralist alternative, it takes the aim of consensus seriously, but, unlike the republican (or civic humanist) alternative, it does not assume that deep agreement or a "shared common ethos" is likely.

However, there is a further role of consensus in deliberative accounts that does seem to require actual agreement in order for (good faith) deliberation to take place. If citizens are to regard the outcome of deliberative procedures as legitimate and "fair" (even if not necessarily right) it would seem that they must all agree that certain values have been sufficiently recognized. This follows from the fact that, according to the deliberative model, the legitimacy or fairness of the procedures is not solely a procedural question. ${ }^{35}$ As I suggested in connection with Habermas's view above, the conception of equality to which he appeals is not the equal consideration of interests procedurally defined, but the equal status of citizens as co-authors of the legal order to which they are bound - that is, a conception of democratic equality. If citizens are not able to agree on a minimal political "core morality" - or if it is not embedded in the democratic institutions of the society - then it is not clear how the outcomes could claim to be legitimate at all.

Critics may reply (and have replied) that this last role of a politicalmoral consensus does not take the fact of moral pluralism seriously enough. ${ }^{36}$ Disagreement is not limited to ethical questions, as Habermas has sometimes suggested, but extends to moral questions, or questions of justice, as well. Similarly, some critics will find Rawls's idea of an overlapping consensus - a political consensus that can emerge despite a

35 For a persuasive defense of this position, see Joshua Cohen's critique of Stuart Hampshire's proceduralism, in "Pluralism and Proceduralism".

36 See, for example, Simon Caney, "Liberal Legitimacy, Reasonable Disagreement, and Justice", in Pluralism and Liberal Neutrality, ed. by R. Bellamy and M. Hollis (London: Frank Cass, 1999), p. 19-36, and Joseph Chan, "Legitimacy, Unanimity and Perfectionism", Philosophy and Public Affairs, 29 (2000), p. 5-42. 
plurality of reasonable comprehensive doctrines - to be similarly suspect. Clearly, many questions of justice are as contestable as ethical questions. However, as I shall argue in the next section, unless there is reason to expect agreement on a minimal core morality it is not clear how any further compromise could be regarded as fair, or how any other distinction between a reasonable (as opposed to an unreasonable) disagreement could be sustained. ${ }^{37}$

\section{The idea of public reason}

The idea of public reason figures importantly in the conceptions of political legitimacy proposed by John Rawls and Jurgen Habermas. However each criticizes the other for shortcomings in their respective approach: Rawls suggests that Habermas's idea of public reason is part of a comprehensive philosophical doctrine and thus unacceptable as a basis of political legitimacy in a society characterized by a plurality of comprehensive views. Habermas, by contrast, suggests that Rawls's model of public reason, with its reliance on the idea of an overlapping consensus, remains too beholden to the contingencies of a de facto agreement to serve as a suitable basis of political legitimacy. Though Rawls is not always as clear about his conception of public reason as he might be, I wish to argue in the following that the positions of Habermas and Rawls are not as far from one another as is often supposed. In particular, though Rawls suggests that his model of public reason is circumscribed and perhaps even constituted by what he calls the 'domain of the political', I believe that when his conception of the political is properly understood - when, that is, it is not "political in the wrong way" - it does not differ significantly from Habermas's own account of public reason. In the end, both accounts of public reason incorporate a core set of liberal values tied, in Rawls's case, to the notion of citizens as free and equal persons with the two basic moral powers and, in Habermas's case, to a notion of communicative autonomy.

Public reason for Habermas refers not only to the sense in which in acting communicatively (or indeed, as I have argued, in acting for a reason at all) a person must suppose that she can justify her action to others.

37 Habermas's basic strategy in response to this challenge is to "go abstract" and argue that in an increasingly pluralist society the bases of agreement shrinks to the terms of fair procedure. My claim in the section that follows is that fair procedures cannot completely ignore (substantive) issues of equal respect and mutual recognition. In fact, the example cited by Bellamy and Hollis - the case of the Lincoln/Douglas debate over slavery - shows precisely why not just any compromise can be considered fair (see "Consensus, Neutrality and Compromise" in Bellamy and Hollis, p. 74-75). 
The idea of public reason also plays a crucial role in Habermas's account of political legitimacy. Basic political norms (e.g., what Rawls calls the "constitutional essentials" and matters of basic justice) are legitimate only if they conform to a demanding ideal of public reason, that is, only if they could be agreed to by all citizens as participants in a practical discourse for the same (publicly available) reasons. Tom McCarthy and others have argued that Habermas's conception of political legitimacy, together with this idea of public reason, is too strongly oriented to the idea of consensus or "rational agreement" and that he should move more in the direction of Rawls's notion of an overlapping consensus which allows for "reasonable disagreement" and "reasonable pluralism" within a public culture. ${ }^{38}$ Political legitimacy neither can nor should depend on such a demanding idea of rational agreement but rather should draw upon the idea of a "mutual accommodation" among diverse worldviews and corresponding forms of life. This revision also entails a more thoroughly "proceduralist" interpretation of political legitimacy.

On the other hand, in an extended engagement with Rawls's work, Habermas has argued that Rawls's notion of an overlapping consensus cannot serve the purpose to which Rawls puts it and that Rawls himself requires a stronger, more consensualist notion of practical reason to support his own liberal principle of legitimacy. ${ }^{39}$ This principle, it will be recalled, reads as follows: "Our exercise of political power is fully proper only when it is exercised in accordance with a constitution the essentials of which all citizens as free and equal may reasonably be expected to endorse in the light of principles and ideals acceptable to their common human reason" 40 or, as he has expressed it in more recently: "Our exercise of political power is proper only when we sincerely believe that the reasons we would offer for our political actions - were we to state them as government officials - are sufficient, and we also reasonably think that other citizens might also reasonably accept those reasons". ${ }^{41}$ According to Habermas, however, Rawls (at least in Political Liberalism) interprets this principle of legitimacy in connection with the de facto emergence of an overlapping consensus rather than, as one should, in terms of a

38 McCarthy, "Legitimacy and Diversity"; see also James Bohman and William Rehg, "Discourse and Democracy: The Formal and Informal Bases of Legitimacy in Between Facts and Norms", in Democracy and Discourse: Essays on Habermas's 'Between Facts and Norms', ed. R. von Schomberg and K. Baynes (Albany: SUNY Press, 2002).

39 See The Inclusion of the Other (Cambridge: MIT Press, 1998), chaps 2 and 3.

40 Rawls, Political Liberalism (New York: Columbia University Press, 1993), p. 137.

41 "The Idea of Public Reason Revisited", The University of Chicago Law Review, 64 (1997), 771. 
more abstract (communication-theoretical) idea of rational agreement or acceptability.

In the following I would like not only to defend Habermas's own position, as I understand it, against McCarthy's "friendly amendment" but also argue that Habermas has misunderstood Rawls's position, which, rightly understood, is in fact much closer to Habermas's own position. Even (or precisely) a liberal principle of political legitimacy requires a substantive (and not merely "indirect" or procedural) agreement on a "core morality" (Larmore) that can be the focus of, or specify the content for, a reasonable overlapping consensus. ${ }^{42}$ However, in contrast to Habermas's reading, this overlapping consensus is not simply a "lucky convergence" that just "happens" to come about. ${ }^{43}$ Rather it can only play an appropriate role in justification if it contributes to social stability, as Rawls puts it, "for the right reason" and is not "political in the wrong way". ${ }^{44}$ I thus agree with Larmore when he writes, "[Rawls] seems clearly not to believe, contrary to some of his recent critics, that the commitments on which his political liberalism rests are simply those that people in modern Western societies share as a matter of fact. What he holds is that these commitments would be the object of consensus to the extent that people view themselves, as they should, as free and equal citizens". ${ }^{45}$ These considerations suggest that the notion of the reasonable (together with his account of public reason) functions for Rawls in a different manner than Habermas has suggested. It also suggests that the procedural/substantive contrast may be overdrawn by several of the participants in this debate. ${ }^{46}$

42 Joshua Cohen also questions attempts to distinguish sharply between "procedure" and "substance" with respect to political values in "Pluralism and Proceduralism", Chicago-Kent Law Review, 69 (1994), 589-618. For Charles Larmore's notion of a "core morality," see his The Morals of Modernity (New York: Cambridge University Press, 1996), where he argues it includes, among other elements, a "norm of rational dialogue" and a "norm of equal respect". Larmore, it should be noted, does not think this "core morality" can be derived from a concept of practical reason alone (see p. 56-57); but he also assumes a conception of practical reason that is more restrictive than Habermas's and one that is too sharply contrasted with tradition.

43 Habermas, Inclusion of the Other, p. 84.

44 "Reply to Habermas", Journal of Philosophy, 92 (1995), 132-180, here p. 142; see also Justice as Fairness: A Restatement, p. 188.

45 Larmore, Morals of Modernity, p. 149; for a similar interpretation of Rawls's later writings, with their focus on "stability for the right reasons", see also Thomas E. Hill, "The Problem of Stability in Political Liberalism", Respect, Pluralism, and Justice (New York: Oxford University Press, 2000), chap. 9.

46 See the important discussion of Joshua Cohen, "Pluralism and Proceduralism" Chicago-Kent Law Review, 69 (1994) and Rawls's own endorsement of this interpretation in his "Reply to Habermas". In effect, neither Rawls nor Habermas are 'proceduralists' in a very strict reading of this term. 
To begin, then, I will briefly review McCarthy's criticisms of Habermas. According to McCarthy, Habermas has not yet articulated a conception of public reason (and, hence, political legitimacy) that can adequately respond to the value pluralism that characterizes liberal-democratic societies. On the one hand, there typically is no homogeneous ethicopolitical culture that could provide the necessary background for an agreement on "constitutional essentials and matters of basic justice". On the other hand, the model of discourse that Habermas proposes does not make sufficient allowance for "reasonable disagreements" about moral/ethical questions. Rather, cases supporting the idea of a reasonable value pluralism are either interpreted as "interim reports" on an on-going moral disagreement, where it is claimed there is only one right answer, or they are too quickly treated as a matter of negotiation and compromise, in just the way that conflicts of "interest" are to be handled. ${ }^{47}$ The result is a certain inadequacy within Habermas's theory in responding to the value pluralism characteristic of modern societies. McCarthy's suggestion is that, to accommodate the fact of reasonable pluralism, Habermas must relinquish the strong claims concerning rational agreement (Einverstaendniss), make room for a notion of mutual accommodation (152) and, consequently, give his theory a still more "procedural twist" (151). By making greater use of his own distinction between direct and indirect justification of a norm, for example, Habermas could allow for the idea of a "reasonable disagreement" on values, while nonetheless still providing citizens with a strong procedural reason for accepting as legitimate those norms and decisions they oppose at a substantive level (128).

An initial interpretive question that should be raised concerning this proposed revision, a question of which McCarthy is aware, concerns the nature of the proceduralism he has in mind. What, for instance, is the relation between the procedural and substantive elements of the theory and how, after this "proceduralist twist", is Habermas's position to be distinguished from the more common varieties of proceduralism in which the "fairness" of the procedure is secured by a much more minimal notion of equal consideration of interests than either Habermas or Rawls would be comfortable with? ${ }^{48}$ As I have attempted to show above, despite Habermas's own frequent use of the term procedural, neither Habermas

47 McCarthy, "Legitimacy and Diversity", p. 150.

48 I have in mind, for example, the views of Brian Barry in "Is Democracy Special?" in Philosophy, Politics and Society, ed. P. Laslett (Oxford: Blackwell, 1979), p. 155-156, or Peter Singer, Democracy and Disobedience (New York: Oxford University Press, 1974). 
(nor Rawls) are proceduralists "all the way down". ${ }^{49}$ Rather, both attempt to mirror in a set of procedures a prior substantive value or set of values - autonomy, in the case of Habermas, and the idea of citizens as free and equal persons, in the case of Rawls. It is these values or ideals that then confer a presumption of reasonableness or fairness on the proposed procedures. ${ }^{50}$

I would like instead to focus here on another general question concerning the use of the term "reasonable" in McCarthy's reference to a "reasonable disagreement" and a "reasonable pluralism". I assume that McCarthy takes over these terms relatively unmodified from Rawls, but I want to suggest that Rawls's own use of them, along with their relation to the idea of an overlapping consensus, has not always been well understood. A correct interpretation, I believe, puts Rawls and Habermas much closer together than either McCarthy or Habermas suppose, since both are committed to the view that there must be a prior agreement on a "core morality" that each citizen can affirm for the same (publicly available) reasons.

The idea of the reasonable is invoked at many levels within Rawls's theory, but its most basic use is with respect to persons: A citizen is reasonable if she is willing to accept and abide by fair terms of cooperation and willing to accept the "burdens of judgment", that is, to acknowledge and abide by the limits of reason. ${ }^{51}$ These two basic virtues of the citizen are themselves understood in connection with what Rawls calls the basic moral powers of the person: the capacity for a sense of justice and the capacity for a conception of the good. These moral powers (or basic human capacities) are part of a moral psychology or conception of the person that, along with the idea of social cooperation, form one of the "fundamental intuitive ideas" found in a liberal political culture and from which his political conception is drawn. Though this idea is according to Rawls not itself part of a comprehensive doctrine or theory of human nature, it is nonetheless part of a general set of normative reflections, informed as well by moral and social-scientific theory, on the basic capacities of human agency. ${ }^{52}$ Like Korsgaard's conception of practical agency, this "fundamental intuitive idea" of the person is

${ }^{49}$ See my "Deliberative Democracy and the Regress Problem: Response to Michelman", The Modern Schoolman, 74 (1997), 333f., and "Democracy and the Rechtsstaat: Habermas's Faktizität und Geltung", in The Cambridge Companion to Habermas, ed. S. K. White (New York: Cambridge University Press, 1995), chap. 9; see also the important discussion by Cohen, "Pluralism and Proceduralism".

${ }^{50}$ See Habermas, Between Facts and Norms, p. 266 and 295; "Reply" in Rosenfeld and Arato, p. 406.

${ }^{51}$ Political Liberalism, p. 49 note 1.

52 Political Liberalism, p. 86-87. 
(I believe) a conception of the agent that "stands behind" our other, more determinate practical identities and is more or less implicitly assumed by many different religious and secular traditions. It refers to the general human capacity to respond to and act for reasons. The appeal to this capacity gives normative content to Rawls's idea of the reasonable and ultimately shapes his notion of a (rational) justification (e.g., what is acceptable to "common human reason").

The further notions of a "reasonable comprehensive doctrine", a "reasonable overlapping consensus," and "reasonable pluralism" all draw upon this prior notion of reasonable persons: a doctrine, for example, is reasonable if its more specific elements fall within the "burdens of judgment" of reasonable citizens and an overlapping consensus is reasonable just in case it is a consensus among reasonable comprehensive doctrines. Finally, a reasonable disagreement is a disagreement that persists even after reasonable people, exercising good faith and recognizing the "burdens of judgment," nonetheless fail to agree on a particular matter. According to Rawls, in a liberal polity such disagreements are to be expected.

It is important to note, however, even in this brief outline, that what Rawls describes as the reasonable is not the conclusion or outcome of an agreement or overlapping consensus that just happens to exist. Rather, the prior idea of the reasonable informs what can count as a reasonable comprehensive doctrine and thus what could finally be part of a (reasonable) overlapping consensus. The idea of the reasonable, in other words, is something that must in this sense be given in advance of any existing overlapping consensus, rather than something that results from it. It might be objected, in response, that this reading does not follow Rawls's own recent distinction between "moral autonomy" and "political autonomy" (or, relatedly, between "persons" and "citizens") and thus still gives Rawls's position a too Kantian interpretation - one his "freestanding" political conception is meant to avoid. ${ }^{53}$ However, though Rawls's own formulations sometimes lend support to such a reading, I think this cannot be his considered position. He is himself explicit that a "political" conception is still a "moral conception" and, in introducing his "criterion of reciprocity" (in which citizens must reasonably think that others can reasonably accept the terms of cooperation proposed), he states that this criterion bars slavery and other violations of basic liberties. ${ }^{54}$ In short, even his conception of the political autonomy of citizens, along

53 See, for example, Rainer Forst, "Die Rechfertigung der Gerechtigkeit" in Das Recht der Republik, ed. H. Brunkhorst and P. Niesen (Frankfurt: Suhrkamp, 1999), p. 105-168.

54 Compare Political Liberalism, p. xliv and li. 
with the terms of social cooperation they could "reasonably" undertake, presupposes the two moral powers or "basic human capacities" Rawls earlier introduced in A Theory of Justice. ${ }^{55}$

A related question often raised in connection with Rawls's political liberalism - and one raised by Habermas - concerns the role that the idea of an overlapping consensus plays in its justification (in contrast to its stability or likelihood to endure over time). ${ }^{56}$ According to Rawls, the idea of an overlapping consensus is first introduced at a second stage, in connection with the question of social stability, not at the first stage when the initial justification of the principles of justice is at issue. This does not mean, however, that the overlapping consensus is not at all relevant to the process of justification. Rawls's considered view seems to be that if it turns out that the political conception justified at the first stage is not stable - that is, could not become the object of a reasonable overlapping consensus - then this would somehow call into question its earlier claim to being justified. ${ }^{57}$

In his own interpretation of Rawls, however, Habermas seems to take a different tack. That is, he attributes a more significant justificatory role to the idea of an overlapping consensus than, I believe, Rawls has in mind. Habermas apparently does not consider that the idea of the reasonable must already be presupposed prior to the identification of those comprehensive doctrines that might be eligible candidates for a reasonable overlapping consensus, but rather regards the notion of the reasonable as itself the outcome of a contingent or "lucky" convergence: "Only the lucky convergence of the differently motivated nonpublic reasons can generate the public validity or 'reasonableness' of the content of this 'overlapping consensus' that everyone accepts. Agreement in conclusions results from premises rooted in different outlooks". ${ }^{58}$ Now, while it is true that each citizen may and even should look to his or her own comprehensive doctrine to see whether he or she has reason to affirm the content of the overlapping consensus, it is not the case either that the justification of the content rests upon these "nonpublic" reasons or that a contingent overlapping consensus produces or defines the "reasonableness" of that content.

55 The distinction between 'moral autonomy' and 'political autonomy' is thus not a claim that political autonomy does not presuppose the (Kantian) moral powers of the person, but rather a claim that these moral powers do not entail the more comprehensive (Kantian) ethic of personal autonomy (see Political Liberalism, p. xlv and the helpful discussion in Larmore, "Political Liberalism" [The Morals of Modernity (CUP, 1996), p. 134-141].

56 Inclusion of the Other, p. 61, 89f.

57 See "Reply to Habermas", p. 142f.

58 Inclusion of the Other, p. 84. 
This repositioning of the reasonable within Rawls's conception of political liberalism also then suggests how Rawls may in fact be closer to Habermas's own position. It is the basic idea of the citizen as reasonable and rational and, behind this, the idea of the basic moral powers of the person that importantly shapes the subsequent employment of the reasonable in Rawls's work. In ways that closely resemble Habermas's basic assumptions about communicative freedom-the capacity to take a position on a speech act offer, Rawls's idea of the reasonable acquires at least some of its normative authority from the fundamental human capacity to respond to and act from reasons: the legitimacy of a political order depends on what citizens can endorse in view of their "common human reason" (though a lot of further philosophical argument - contained in A Theory of Justice and Political Liberalism - is required to show what kind of political order might possibly satisfy this requirement).

Given McCarthy's reservations about Habermas's model of public reason sketched above, his response to this reading of Rawls might simply be, "Well, so much the worse for him!" If the best reading of Rawls is one that also commits him to a stronger, more consensualist model of political legitimacy, then perhaps he too should be urged to move more in the direction of McCarthy's proceduralism and idea of "mutual accommodation". However, I do not believe this is an option for McCarthy because I do not think he is able to make a convincing case that his proposed revision constitutes a real alternative to Habermas. It only seems to be a real alternative because McCarthy does not clarify what he means by a reasonable pluralism and a reasonable disagreement. How are these to be distinguished from their unreasonable counterparts? I see no alternative to the view that a disagreement is reasonable only if there exists at another level an agreement on core values that all can accept for the same publicly available reasons - in the last analysis, values based on our conception of ourselves as free and equal persons. We could think a disagreement arose from the "burdens of judgment" rather than willful ignorance or prejudice only if there were a further agreement on other basic values. Similarly, we can "(reasonably) agree to disagree (reasonably)" (McCarthy) only if we believe other procedures that are available for regulating our coexistence at a more abstract level reflect norms and values that all could accept for the same (publicly available) reasons. In short, it would not be a reasonable pluralism or a reasonable disagreement if there were not (or could not) be this deeper agreement. McCarthy rightly notes that Habermas's discussion of practical rationality does not adequately address ways to handle cases of reasonable disagreement, but I do not think a more adequate or 
nuanced account can finally break with Habermas's criterion of rational acceptability. ${ }^{59}$ As Habermas points out in his reply to McCarthy, even McCarthy's treatment of tolerance and mutual accommodation seem to presuppose the ideal of a rationally motivated agreement. ${ }^{60}$

\section{The practice of public reason}

In concluding I will briefly consider some implications this more abstract debate regarding the idea of public reason might have for more concrete political practice. In particular, I want to suggest some ways that it might inform both the practice of toleration and the practice of political public reasoning.

(a) As many commentators have pointed out, toleration is an important yet elusive liberal virtue. ${ }^{61}$ It asks that we live with what we might find deeply repugnant from a personal point of view. In this respect, it is an attitude that, despite its almost banal ring, is both extremely demanding and indispensable to a liberal political culture: On the one hand, we may personally (and justifiably) feel quite opposed to the practice or way of life we are asked to tolerate, yet, on the other hand, we are asked actively to affirm the right of others to engage in that practice or way of life (even though we need not have any regret should that practice or way of life cease to exist). ${ }^{62}$ How is it possible to cultivate such an attitude, particularly in a pluralist society where we are likely to frequently encounter attitudes and ways of life with which we disagree? And, secondly, what are the appropriate limits of such an attitude: is it necessary to tolerate the intolerable? Is not this paradoxical virtue simply one more symptom of an impoverished liberalism that finds itself obliged to defend practices it finds morally offensive? These are not easy questions to answer but several brief observations can be made. Habermas's distinction between a political culture and the larger societal culture, as well as Rawls' parallel distinction between what he calls the "politically public" and the larger background culture, is important here inasmuch as the first term in these pairs helps to set the basic frame and limits of the tolerable. In this respect it defines the minimal "core morality" the violation of which need not be tolerated,

59 For some important suggestions on this topic, see James Bohman, Public Deliberation (Cambridge: MIT Press, 1996).

60 Habermas, "Reply", p. 402.

61 See David Heyd, ed., Toleration: An Elusive Virtue (Princeton: Princeton University Press, 1996).

62 See T. M. Scanlon, "The Difficulty of Tolerance" in Toleration, ed. Heyd, and Habermas's remarks in his "Reply", Habermas on Law and Democracy, p. 393. 
either from a legal or a moral point of view. ${ }^{63}$ (I do not mean that, as a matter of policy, questions such as the legal regulation of hate speech or violent pornography are now immediately settled; but rather that this core morality provides the general framework within which a political community is first properly bound to address those topics). At the same time, however, matters that do not concern the "core morality" of the political culture are ones that all citizens have an obligation to tolerate as a matter of public morality. It may also be that, as part of an attitude of toleration, citizens also have an obligation to try to reach a greater mutual understanding of one another's perspective. The exercise of toleration thus may (but need not) develop into stronger forms of appreciation and "civic friendship".

(b) In the context of his exchange with Rawls, Habermas has defended a conception of public reason and corresponding conception of "reasonableness" as an important political virtue and one that is probably as demanding as the virtue of toleration. In connection with his version of "political liberalism" based on the idea of an "overlapping consensus" among divergent comprehensive moral or religious worldviews, Rawls has argued that, as a duty of civility, citizens have a moral obligation, when they consider how to cast their vote, to regard themselves as "ideal legislators" and ask whether the reasons in support of the proposed legislation or policy are ones that it is reasonable to think other citizens could also endorse. In response to criticisms of his initial formulation, he now endorses what he calls an "inclusive" model of public reason which allows citizens to act from reasons drawn from their comprehensive moral or religious convictions so long as they believe the positions they support could "in due course" also be supported on the basis of public reasons that all affected could acknowledge on the basis of their shared conception of themselves as free and equal persons. ${ }^{64}$ Rawls goes on to indicate that this "duty" applies only to political discussions within the "public political forum" and not to discussion within the larger "background culture" of civil society. ${ }^{65}$ Thus, while it is permissible for a person to advocate laws, say, prohibiting samesex marriages in various associations and fora of civil society, it would be inappropriate for that same person to make such an argument in a political forum where it is not reasonable for him or her to assume that the co-participants (and co-citizens) could share the same grounds of the

63 I draw this idea of a shared "core morality" from Larmore, Morals of Modernity, p. 12-13.

64 Rawls, "The Idea of Public Reason Revisited", p. 776, 784.

65 Rawls, “The Idea of Public Reason Revisited," p. 768, 775 n. 28. 
argument. ${ }^{66}$ Nonetheless, it is clear that this still represents a quite demanding requirement for public reason.

In his own reflections Habermas is led to a similar conception of public reason and, if anything, gives it an even stronger interpretation. ${ }^{67} \mathrm{He}$ writes: "Anything valid should also be capable of a public justification. Valid statements deserve the acceptance of everyone for the same reasons". ${ }^{68}$ Thus, for Habermas, though it may indeed be possible for individuals to embed their shared political ideals within their own comprehensive moral or religious worldviews, this connection between private moralities and public reason does not provide a sufficiently stable or normatively appropriate basis for the legitimate exercise of coercive political authority. Rather, citizens must simultaneously both presuppose and strive to articulate a basic political consensus (focused on the idea of a "core morality" mentioned above) that all citizens can endorse as valid for the same (publicly available) reasons. The legitimate exercise of political power requires that the reasons that justify at least the basic principles of justice and "constitutional essentials" be ones that all citizens can endorse for the same reasons - that is, in view of their shared conception of themselves as free and equal persons. Moreover, the political virtue of reasonableness requires that citizens, in regarding themselves as 'ideal legislators', seek to find for the policies and legislation they support reasons that they reasonably believe others could reasonably endorse.

Two important objections to this account of the civic virtues need to be addressed: are they themselves exclusionary and/or sectarian in conception?, and is it at all plausible to think that they can be effectively promoted and sustained within the two-track model of deliberative democracy advocated by Habermas?

(1) The first objection, which has been raised from some quite diverse perspectives, is that the virtues of toleration (and reasonableness) are

66 Rawls, it seems to me, is in fact unclear as to whether this constraint applies to all citizens or only to legislators and candidates for public office (see p. 767-68 and 769 , where he suggests that all citizens are to think of themselves as if they were legislators).

67 Habermas, “'Reasonable' versus 'True', or the Morality of Worldviews," Inclusion of the Other, chap. 3. Though, as I will argue, this is not the most charitable way to read Rawls, it is one that is widely shared; see for example Joseph Raz, "Facing Diversity: The Case for Epistemic Abstinence", Philosophy and Public Affairs, 19 (1990). 3-46.

68 Habermas, “'Reasonable' versus 'True'”, p. 86; see also his "Some Further Clarifications of the Concept of Communicative Rationality," Pragmatics of Communication, p. 321, where he writes: "Agreement [Einverständniss] in the strict sense is achieved only if the participants are able to accept a validity claim for the same reasons". 
not innocent but rather function in ways that are both exclusionary and sectarian. Although this objection raises a number of extremely complex issues, I want to claim in response that, when properly understood, these virtues do not have to have the exclusionary consequences its critics have claimed. While Kirstie McClure, for example, may be right that the practice of toleration asks, say, religious believers to regard the truth claims of their faith as matters of private belief, it does not follow that it constitutes an unjustifiable or unacceptable harm against them. ${ }^{69}$ There is no guarantee that within a liberal polity matters of religious faith and practice or, for that matter, other individual or collective ways of life will remain unchanged. The question must be whether or not individuals have their equal rights and liberties denied them in their treatment by the state. It does not seem to constitute a harm or violation of a right to, say, freedom of speech, if one is told that he or she is not morally entitled, in certain political fora, to press claims against others that others do not (and cannot reasonably be expected to) acknowledge. Similarly, the claim that citizens act unreasonably if they promote policies and legislation on the basis of non-public reasons does not per se imply that they themselves are the victims of exclusionary or sectarian politics. On the one hand, to claim that it is a violation of a moral duty to pursue positions on the basis of non-public reasons within the more narrowly circumscribed political public sphere does not mean that there are not many other fora available within civil society in which those views can be aired and discussed. Secondly, I have again not broached the difficult topic of when (or whether) it is permissible to respond to such moral infractions with legal remedies (e.g., the legal regulation of hate speech). ${ }^{70}$ Rather, my more general and limited point has been to claim that the civil duty of toleration does not necessarily imply an (unjustifiable) exclusion of others or their points of view.

A slightly different version of this objection can be found in the claim that the "discipline of public reason" is too harsh in that it will require individuals to argue their opinions in a form that will strike them as foreign or insincere. If comprehensive doctrines and philosophies of life must be left at the entrance to political assembly and arguments presented in

69 Kirstie McClure, Judging Rights: Lockean Politics and the Limits of Consent (Ithaca: Cornell University Press, 1996), p. 199.

70 See, however, the cautious defense of a regulation of hate speech by Joshua Cohen, "Freedom, Equality and Pornography" in Justice and Injustice in Law and Legal Theory, ed. by A. Sarat and T. Kearns (Ann Arbor: University of Michigan Press, 1996), p. 99-137, and the very interesting critique of liberal arguments against the regulation of hate speech by Susan Brison, "The Autonomy Defense of Free Speech", Ethics, 108 (1998), 312-339. 
terms of public reasons that others could acknowledge citizens may not even recognize themselves in their positions and, ironically, this requirement of reciprocity may inhibit the aim of mutual understanding. ${ }^{71}$ According to Daniel Weinstock, Rawls's assumption that public reason functions like a "module" that can be attached (or detached) from any (reasonable) comprehensive doctrine rests on a questionable psychology of beliefs since the "fit" between public and "private" reasons may be much tighter for many citizens. As an example - mine, not Weinstock's - consider Catherine MacKinnon's description of our gendered society: "Men's physiology defines most sports, their needs define auto and health insurance coverage, their socially designed biographies define workplace expectations and successful career patterns, their perspectives and concerns define quality in scholarship, their experiences and obsessions define merit, their objectification of life defines art, their military service defines citizenship, their presence defines family, their inability to get along with each other - their wars and rulerships - defines history, their image defines god, and their genitals define sex". ${ }^{72}$ It is difficulty to imagine how this criticism of the sexism in social life could be as effective if it were to be expressed in the language of public reason - or how it could be expressed with the same conviction.

However, I believe this version of the objection misses the point of - and motivation for - the idea of public reason, at least in Habermas and Rawls. First, as I indicated above (and as Weinstock also notes), the expectation that reasoning be public (or that reciprocity be exercised) applies only to certain political fora and not within the wider "background" culture or in what Habermas calls "civil society". Such a wide constraint would surely undermine, as Weinstock argues, both mutual understanding and individual autonomy. More importantly, however, Rawls's account of public reason leaves citizens free to find the deeper roots of their convictions about the political values in their comprehensive views and thus does not ask them to sacrifice their non-political identity when they are asked to argue (again in certain contexts) from their shared pool of public reasons. It does assume, however, that they are capable of drawing a distinction between their common political identity as citizens and whatever further identities they may possess.

(2) The second objection is equally challenging: Is it in fact reasonable to assume that in a civil society characterized as "wild" and "anarchic"

71 See Daniel Weinstock, "Saving Democracy from Deliberation" in: Canadian Political Philosophy, ed. by R. Beiner and R. Norman (New York: Oxford University Press), 78-91.

72 Catherine MacKinnon, Feminism Unmodified (Cambridge: Harvard University Press, 1987), p. 36. 
the social and cultural conditions will exist that would be required for the promotion and maintenance of the civic virtues of toleration and reasonableness? Habermas is himself quite aware of this challenge: "On account of its anarchic structure, the general public sphere is ... more vulnerable to the repressive and exclusionary effects of unequally distributed social power, structural violence, and systematically distorted communication than are the institutionalized public spheres of parliamentary bodies". ${ }^{73}$ There can thus be, it seems, no guarantee that the associations arising within civil society will not be "tribalistic", inegalitarian, or ones that contribute to a culture of group bias and discrimination. Can a liberal political culture be fashioned and sustained under such conditions? It is unlikely that a definitive answer can be given to this question one way or the other. Many empirical and normative assumptions are involved. However, at least until we have more evidence to the contrary perhaps we should not be overly pessimistic about the possibilities for wider civility even in the face of a civil society that is deeply pluralistic and even "anarchic". On the one hand, the form of civility that is required for a democratic polity may not need to be as "thick" as some communitarians and others have supposed. What is required, it would seem, is a liberal political culture that is based on, and incorporates in its own norms of civility, the "core morality" mentioned above. The bonds of civility may not have to reach so deeply into particular and often sectarian worldviews that it threatens their (at any rate always fluid) identities, and it may be possible to embrace the central elements of a core morality from the perspective of otherwise very different worldviews. (This, I take it, is the important lesson to be learned from Rawls's idea of an overlapping consensus). ${ }^{74}$

On the other hand, it is perhaps also the case that we have not sufficiently explored the ways in which government, through its regulatory policy, can help to promote the minimal bonds of civility. This indeed may be one of the major differences between the liberal egalitarianism of the welfare state and Habermas's "two-track" model of a deliberative politics. ${ }^{75}$ The largely interventionist and regulatory practices of the liberal welfare state, some have argued, may be counterproductive to their own

73 Between Facts and Norms, p. 307-308.

74 See Ravls's Political Liberalism as well as the argument for mutual respect based on a principle of reciprocity despite deep moral disagreement, found in Amy Gutmann and Dennis Thompson, Democracy and Disagreement (Cambridge: Harvard University Press, 1996).

75 See Habermas's discussion of a new legal paradigm, in contrast to both the classical liberal and the welfare state paradigms, in Between Facts and Norms, chapter 9. 
intended effects. ${ }^{76}$ What is required - though it is by no means an easy task - is a focus on the (limited) ways in which the state, in cooperation with institutions of civil society, can help to foster the virtues necessary for a liberal political culture. ${ }^{77}$

${ }^{76}$ See, among others, Avishai Margalit, The Decent Society (Cambridge: Harvard University Press, 1996).

${ }^{77}$ See on this the interesting proposal concerning the use of the "intangible hand" of the state for such a purpose in Philip Pettit, Republicanism (Oxford: Clarendon, 1997). 